\title{
Time to diagnosis of tuberculosis is greater in older patients: a retrospective cohort review
}

\author{
Aula Abbara ${ }^{1,2}$, Simon M. Collin $\mathbb{1}^{3}$, Onn M. Kon (102,4, Kevin Buell ${ }^{2}$, \\ Adam Sullivan ${ }^{2}$, Jessica Barrett ${ }^{1}$, Tumena Corrah ${ }^{1}$, Alastair McGregor ${ }^{1}$, \\ Trevor Hansel ${ }^{2}$, Laurence John ${ }^{1}$ and Robert N. Davidson ${ }^{1}$
}

Affiliations: ${ }^{1}$ London North West University Healthcare NHS Trust, London, UK. ${ }^{2}$ Dept of Infection, Imperial College London, London, UK. ${ }^{3}$ Public Health England, London, UK. ${ }^{4}$ Imperial College Healthcare NHS Trust, London, UK.

Correspondence: Aula Abbara, Dept of Infection, Imperial College Healthcare NHS Trust, St Mary's Hospital, Praed Street, London, W2 1NY, UK. E-mail: a.abbara15वimperial.ac.uk

\section{ABSTRACT}

Introduction: Age-related immunosenescence influences the presentation of tuberculosis (TB) in older patients. Here, we explore the clinical and radiological presentation of TB in the elderly and the factors associated with time to treatment for TB.

Methods: This is a retrospective cohort study comparing the clinical, radiological and demographic characteristics of TB patients aged $\geqslant 65$ years with TB patients aged 18-64 years in a large cohort of TB patients in the UK. Factors associated with the time to presentation and time to treatment were identified using a multivariable analysis model.

Results: 1023 patients were included in the analyses: 679 patients aged 18-64 years and 344 patients aged $\geqslant 65$ years. "Classical" symptoms of TB (cough, haemoptysis, fever, nights sweats and weight loss) were less common among older patients with pulmonary TB (PTB) $(\mathrm{p}<0.05)$, but dyspnoea was more common among older patients $(\mathrm{p}=0.001)$. Time from presenting in secondary care to starting treatment was shorter in younger compared with older patients: 3 versus 15 days $(\mathrm{p}=0.001)$. When adjusted for age, factors associated with shorter time to treatment from symptom onset include sex (male versus female) (hazard ratio (HR) 1.23 (95\% CI 1.05-1.46)), UK born (HR 1.23 (95\% CI 1.05-1.46)) and HIV (HR 2.07 (95\% CI 1.30-3.29)). Only age remained an independent predictor of time to treatment in a multivariable model (HR 0.98 (95\% CI 0.98-0.99)). For those with PTB, chest radiography findings showed that cavitation and lymphadenopathy were more common among younger patients $(\mathrm{p}=0.001)$.

Conclusions: Older patients aged $\geqslant 65$ years with TB had fewer "classical" clinical and radiological presentations of $\mathrm{TB}$, which may explain longer times to starting treatment from symptom onset compared with younger patients aged $<65$ years.

@ERSpublications

A retrospective UK study in patients with TB shows only age remains an independent predictor of time to treatment in a multivariable model. Older patients have fewer of the "classical" clinical and radiological features of TB compared with younger patients. http://bit.ly/2yHc0OL

Cite this article as: Abbara A, Collin SM, Kon OM, et al. Time to diagnosis of tuberculosis is greater in older patients: a retrospective cohort review. ERJ Open Res 2019; 5: 00228-2018 [https://doi.org/ 10.1183/23120541.00228-2018].

This article has supplementary material available from openres.ersjournals.com.

Received: 29 Nov 2018 | Accepted after revision: 29 July 2019

Copyright $\odot$ ERS 2019. This article is open access and distributed under the terms of the Creative Commons Attribution Non-Commercial Licence 4.0. 


\section{Introduction}

Age-related changes to the innate and adaptive immune system can increase susceptibility to tuberculosis (TB) infection or the reactivation of latent TB infection (LTBI) in older patients [1]. The global increase in ageing means that those aged $\geqslant 65$ years are expected to account for $16 \%$ of the world's population by 2050, a proportion expected to rise much faster in developing countries (a 250\% increase) compared with developed countries (a 71\% increase) [2]. More than 95\% of the burden of TB is in low- and middle-income countries (LMICs) $[3,4]$, with the older population increasing as a proportion of patients with TB $[5,6]$. There is also likely to be a burden of undetected TB among the elderly, particularly in LMICs [4]. For older patients, the higher rate of TB is likely a combination of cumulative years with LTBI, age-related immunosenescence, comorbidities and immunosuppressive therapy [4].

TB in the elderly presents with fewer of the classical symptoms of TB [1,6-9], less specific radiological changes $[10,11]$ and more comorbidities $[9,12]$ than in younger patients, and it has even been proposed that TB in older adults should be considered as a different disease entity [13]. The classical TB symptoms of cough, haemoptysis, fever, drenching night sweats and weight loss may not be as evident in older patients. Less specific symptoms, such as weakness, dyspnoea, anorexia and mental change, are seen more frequently in older patients with $\mathrm{TB}$ compared with younger patients $[1,13,14]$. In addition, comorbidities that are more common in older patients may mask the symptoms of TB, e.g. those with chronic cough due to chronic obstructive pulmonary disease (COPD) may have a delayed presentation or diagnosis. However, conversely, they may have closer healthcare contact.

UK surveillance data show that the proportion of TB patients who experienced a delay of $>4$ months from symptom onset to starting treatment increases with age, from $24.9 \%$ in those aged $15-44$ years to $38.6 \%$ among those aged $\geqslant 65$ year olds [15]. The reasons for this are numerous, and likely relate to a combination of patient-related and health system delays. Patient-related delay refers to the time from symptom onset to first seeking healthcare, whereas provider delay occurs within the healthcare system [16]. The less typical symptomatology and radiology among the elderly contributed to patient and healthcare system-related delays in some $[10,17,18]$ but not all cohorts $[19,20]$. For patient-related delays, there may be challenges to recall of type and duration of symptoms on presenting either to secondary care; this may be disproportionately affect older compared with younger patients with TB.

There are few recent studies that explore the differences between older and younger TB patients in a UK setting. TB in older adults is increasingly important given ageing in LMICs where the burden of TB is greatest. It is associated with comorbidities and polypharmacy, increased side-effects, and poorer outcomes, thereby placing increased demand per patient on clinical services [21]. In this study, we compare the clinical and radiological presentation of $\mathrm{TB}$ in adult patients aged 18-64 or $\geqslant 65$ years and factors (including age) associated with time to diagnosis and treatment in a London-based cohort. This cohort represents a high TB burden area in an otherwise low TB incidence country, which may be similar to other urban areas in Western Europe.

\section{Methods}

\section{Study design}

We undertook a retrospective study comparing patients aged $\geqslant 65$ years with patients aged 18-64 years. The aim was to compare the clinical and radiological features at presentation to secondary care, the duration of symptoms at presenting to secondary care, the time from presentation to secondary care to starting treatment and the total time from symptom onset to starting treatment between the two groups.

Factors that may influence time to presentation and treatment were examined: age, ethnicity, place of birth (UK born versus non-UK born), sex, comorbidities (diabetes, renal failure, cancer, HIV and respiratory conditions, including COPD, asthma, bronchiectasis and pulmonary fibrosis). In addition, we also analysed differences by site of TB (extrapulmonary TB (EPTB) versus pulmonary $\mathrm{TB}$ (PTB)) and $\mathrm{PTB}$ smear status.

\section{Study site and patient cohort}

A list of all patients treated for TB at Northwick Park Hospital (London, UK) between 2002 and 2015 was downloaded from the London TB Register. All TB patients aged $\geqslant 65$ years who began treatment from January 1, 2002 to December 31, 2015 were included. We randomly selected a twofold larger sample of patients aged 18-64 years from the register for the period 2011-2015 (because clinical data recording improved from 2011 onwards). Northwick Park Hospital is part of London North West Healthcare NHS Trust, which has one of the largest TB units in the UK (and in Western Europe), treating 600 TB patients per year during 2010-2014. 


\section{Data collection}

The following data were extracted from electronic records in secondary care: symptoms (nature of symptoms and symptom duration at presentation to secondary care, including presence of cough, haemoptysis, fever, drenching night sweats, weight loss, dyspnoea, lethargy and reduced appetite), clinical (site or sites of $\mathrm{TB}$ ) and baseline radiology (chest radiograph most closely preceding start of treatment with features including cavitation, consolidation, nodules, miliary, lymphadenopathy and effusion). For radiology, data were extracted from reports when each of the parameters of interest was reported. Cavitations imply the presence of a cavity; nodules are small masses of tissue visible seen on chest radiography; miliary refers to the presence of uniformly distributed $1-3 \mathrm{~mm}$ diameter nodules on chest radiography.

Data were also collected on baseline biochemistry and haematology (full blood count, erythrocyte sedimentation rate, renal function, electrolytes, albumin, alanine aminotransferase, alkaline phosphatase, bilirubin and 25-hydroxy-vitamin $\mathrm{D}$ level), and treatment (time to starting treatment and symptom onset to starting treatment). Access to primary care records was not possible except where referral letters were uploaded onto the secondary care system.

Baseline biochemical and haematological data were extracted from medical records for groups of patients aged $\geqslant 65$ and $25-35$ years. Data from patients aged $25-35$ years were chosen in order to compare elderly patients with patients in the age range representing the majority of TB patients in our centre.

Time to presentation and start of treatment

To investigate possible age-related delays in treatment and other factors potentially associated with treatment delays, time periods were classified as: 1) pre-secondary care (i.e. before first attendance at hospital), encompassing patient-related and primary healthcare factors, hereafter referred to as "time to presentation" (this period is affected by recall bias of what is reported by the patient either in primary care or secondary care and what is recorded in the primary care referral letter to secondary care); 2) post-secondary care (i.e. after attendance at hospital), describing the period between being first seen at secondary care to starting treatment for TB, hereafter referred to as "time from presentation" (this includes time for investigations); and 3) total time from symptom onset to commencing TB treatment, hereafter referred to as "time to treatment". These chosen time periods encompass the patient's journey from symptom onset to starting treatment and allow for comparison with published literature.

\section{Statistical analysis}

Baseline (at time of admission) demographic and clinical characteristics of patients aged $\geqslant 65$ years were compared with characteristics of patients aged 18-64 years using the Chi-squared test (or Fisher's exact test for cell frequencies $<5)$ for categorical variables $(\alpha=0.05)$ and the Kruskal-Wallis test for continuous variables $(\alpha=0.05)$.

Time periods were presented as median (interquartile range (IQR)) and were also categorised into $<2,2-4$ and $>4$ months. Differences between age groups were tested using the Chi-squared, Fisher's exact and Kruskal-Wallis tests, and were presented using Kaplan-Meier survival curves (with the log-rank test). Cox regression was used to investigate factors associated with each time period. Associations were expressed as hazard ratios (HRs), with $\mathrm{HR}>1$ indicating a faster rate (shorter time) and $\mathrm{HR}<1$ indicating a slower rate (longer time). Univariate and age-adjusted models (using age as a continuous exposure variable) were fitted, and factors that had evidence $(\mathrm{p}<0.1)$ of an association with time period (after adjustment for age) were carried forward to a (fully adjusted) multivariable model. All models were probability weighted to take into account sampling from the patient population aged 18-64 years.

Statistical analyses were performed using Stata version 13 (StataCorp, College Station, TX, USA).

\section{Ethics}

Ethics were reviewed by the Research and Development Dept of London North West Healthcare NHS Trust. Given the retrospective nature of the data, which were collected from routine clinical practice, the recommendation was that research ethics approvals from the Health Research Authority were not required.

\section{Results}

\section{Patient characteristics}

Age, ethnicity and place of birth

1023 patients were included in the analyses: 679 patients aged 18-64 years and 344 patients aged $\geqslant 65$ years (table 1 ).

$61.6 \%$ of the younger group and $56.7 \%$ in the older group were male $(p=0.13)$. Ethnicity was distributed differently across the two age groups $(\mathrm{p}=0.001)$ : South Asian ethnicity (Indian, Afghani, Nepalese, 


\begin{tabular}{|c|c|c|c|}
\hline & $\begin{array}{l}\text { Younger patients } \\
\text { (18-64 years) }\end{array}$ & $\begin{array}{l}\text { Older patients } \\
(\geqslant 65 \text { years })\end{array}$ & p-value \\
\hline Patients & 679 & 344 & \\
\hline Age years & $31(26-42)$ & 73 (69-78) & \\
\hline Sex & & & 0.13 \\
\hline Female & $261(38.4)$ & 149 (43.3) & \\
\hline Male & $418(61.6)$ & $195(56.7)$ & \\
\hline Ethnicity & & & 0.001 \\
\hline Afghani & $11(1.6)$ & $9(2.6)$ & \\
\hline Black & $89(13.1)$ & $44(12.8)$ & \\
\hline Indian & $437(64.4)$ & $193(56.1)$ & \\
\hline Nepalese & 25 (3.7) & $6(1.7)$ & \\
\hline Pakistani & $32(4.7)$ & $14(4.1)$ & \\
\hline Sri Lankan & $17(2.5)$ & $11(3.2)$ & \\
\hline White & $42(6.2)$ & 53 (15.4) & \\
\hline Other & $26(3.8)$ & $14(4.1)$ & \\
\hline UK born & $56(8.2)$ & $39(11.4)$ & 0.10 \\
\hline HIV positive & $12(2.8) n=431$ & $1(0.9) n=112$ & 0.24 \\
\hline \multicolumn{4}{|l|}{ Site of TB } \\
\hline Pulmonary & 243 (35.8) & $169(49.1)$ & \\
\hline Extrapulmonary & $436(64.2)$ & 175 (50.8) & 0.001 \\
\hline Pleural & $74(10.9)$ & $45(13.1)$ & 0.30 \\
\hline Intrathoracic lymph node & $117(17.2)$ & $46(13.4)$ & 0.11 \\
\hline Extrathoracic lymph node & $218(32.1)$ & 63 (18.3) & 0.001 \\
\hline Gastrointestinal & $49(7.2)$ & $20(5.8)$ & 0.39 \\
\hline Central nervous system & $20(3.0)$ & $11(3.2)$ & 0.82 \\
\hline Spinal & $46(6.8)$ & 27 (7.9) & 0.53 \\
\hline Miliary & $13(1.9)$ & $15(4.4)$ & 0.02 \\
\hline \multicolumn{4}{|l|}{ Culture results } \\
\hline $\begin{array}{l}\text { M. tuberculosis culture positive } \\
\text { (all cases) }\end{array}$ & $388(65.4)$ & 177 (61.0) & 0.20 \\
\hline $\begin{array}{l}\text { M. tuberculosis culture positive } \\
\text { (PTB) }\end{array}$ & $162(73.0)$ & $100(69.0)$ & 0.41 \\
\hline Smear positive (PTB) & $67(29.1)$ & $33(25.0)$ & 0.40 \\
\hline \multicolumn{4}{|l|}{ Biochemistry } \\
\hline $\mathrm{ESR} \mathrm{mm} \cdot \mathrm{h}^{-1}$ & $33(13-67) n=273$ & $28(18-72) n=205$ & 0.04 \\
\hline Albumin $\mathrm{g} \cdot \mathrm{L}^{-1}$ & $37(31-39) n=318$ & $33(28-39) n=287$ & $<0.001$ \\
\hline$A L T$ IU. $L^{-1}$ & $21(14-36) n=317$ & $19(12-29) n=287$ & 0.007 \\
\hline$A L T>50 \mathrm{IU} \cdot \mathrm{L}^{-1}$ & $41(12.9) n=317$ & $34(9.9) n=345$ & \\
\hline ALP IU. $L^{-1}$ & $91(77-112) n=318$ & $96(79-128) n=287$ & 0.005 \\
\hline Bilirubin $\mu \mathrm{M} \cdot \mathrm{L}^{-1}$ & $8(6-11) n=312$ & $8(6-12) n=285$ & 0.77 \\
\hline Sodium $\mathrm{mmol} \cdot \mathrm{L}^{-1}$ & $138(136-140) n=317$ & $137(133-140) n=286$ & 0.001 \\
\hline Creatinine $\mu \mathrm{M} \cdot \mathrm{L}^{-1}$ & $63(57-69) n=317$ & $86(68-105) n=286$ & $<0.001$ \\
\hline Creatinine $>112 \mu \mathrm{M} \cdot \mathrm{L}^{-1}$ & $3(0.9) n=318$ & $71(22.2) n=320$ & $<0.05$ \\
\hline Vitamin D nmol. $\mathrm{L}^{-1}$ & $1(1-8) n=275$ & $6(1-31) n=205$ & 0.001 \\
\hline Vitamin $D>50 \mathrm{nmol} \cdot \mathrm{L}^{-1}$ & $1(0.4) n=275$ & $36(17.6) n=205$ & 0.001 \\
\hline
\end{tabular}

Data are presented as $\mathrm{n}$, median (interquartile range) or $\mathrm{n}(\%)$, unless otherwise stated. $M$. tuberculosis: Mycobacterium tuberculosis; PTB: pulmonary TB; ESR: erythrocyte sedimentation rate; ALT: alanine aminotransferase; ALP: alkaline phosphatase.

Pakistani and Sri Lankan) accounted for $76.9 \%$ of cases in younger patients and $67.8 \%$ of cases in older patients, while the proportion of White patients was $6.2 \%$ in the younger cohort and $15.4 \%$ in the older cohort.

\section{Biochemistry and vitamin D levels}

There was evidence of differences in all biochemistry measures except bilirubin. Vitamin D levels differed significantly between the two groups, but both were low at a median of 1 and $6 \mathrm{nmol} \cdot \mathrm{L}^{-1}$ for younger and older patients, respectively. Only $0.4 \%$ of patients aged $<65$ years versus $17.6 \%$ of patients aged $\geqslant 65$ years had a vitamin D level $>50 \mathrm{nmol} \cdot \mathrm{L}^{-1}$. 


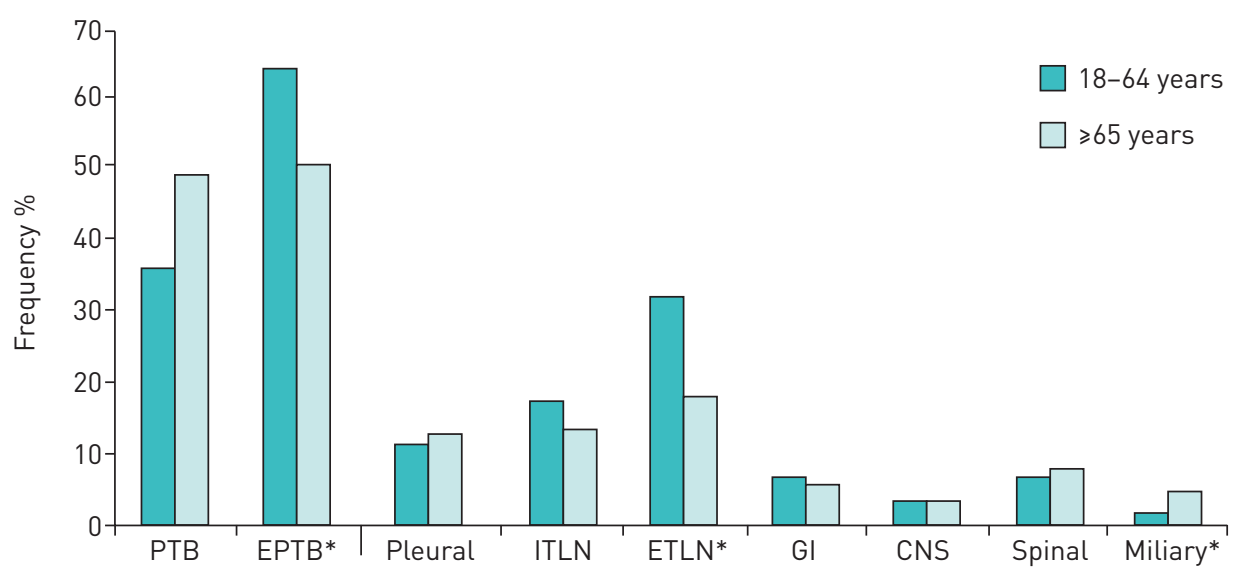

FIGURE 1 Site of tuberculosis (TB) in the younger group laged 18-64 years) and the older group laged $\geqslant 65$ years): pulmonary TB (PTB) versus extrapulmonary TB (EPTB), with specific sites for EPTB also shown. ITLN: intrathoracic lymph node; ETLN: extrathoracic lymph node; GI: gastrointestinal; CNS: central nervous system. *: $p<0.05$.

\section{Site of TB}

$35.8 \%$ of younger patients and $49.1 \%$ of older patients had PTB ( $\mathrm{p}=0.001)$ (table 1 and figure 1$)$. Extrathoracic TB lymphadenitis was less common ( $18.3 \%$ versus $32.1 \%$; $\mathrm{p}=0.001)$ and miliary TB more common $(4.4 \%$ versus $1.9 \%$; $=0.02)$ in older compared with younger EPTB patients.

\section{Clinical symptoms}

The "classical" symptoms of TB, including cough, haemoptysis, fever, drenching night sweats and weight loss, were more common among PTB patients in the younger cohort $(\mathrm{p}<0.05)$ (table 2$)$. When EPTB patients were included the differences remained for cough, fever, drenching night sweats and dyspnoea, but not for haemoptysis and weight loss. The less specific symptoms of dyspnoea, lethargy and reduced appetite were more common among older patients when all sites of TB were included, but only dyspnoea was statistically significant.

\section{Radiology}

There were some differences in the chest radiography appearance of PTB patients: cavitation was more common among younger than older patients ( $18.3 \%$ versus $10.3 \%$; $=0.001$ ), as was lymphadenopathy ( $19.5 \%$ versus $4.1 \%$; $\mathrm{p}=0.001)$. Apparent differences in nodules $(16.1 \%$ versus $10.3 \%)$ and effusions $(13.7 \%$ versus $7.2 \%$ ) were not supported by statistical evidence (table 3). Miliary TB was seen more frequently in older patients ( $4.1 \%$ versus $2.9 \%$ ) and mirrored the rates of clinically classified miliary TB. Around half of the patients in both groups had consolidation on their chest radiographs.

\section{TABLE 2 Symptoms at presentation of the younger group (aged 18-64 years) and the older group (aged $\geqslant 65$ years) with} tuberculosis (TB) and pulmonary TB (PTB)

\begin{tabular}{|c|c|c|c|c|c|c|}
\hline & \multicolumn{3}{|c|}{ All TB patients } & \multicolumn{3}{|c|}{ PTB patients } \\
\hline Cough & 236 (37.5) & 38 (27.9) & 0.035 & 140 (64.2) & $31(43.1)$ & 0.002 \\
\hline Haemoptysis & $32(5.1)$ & $2(1.5)$ & 0.063 & $27(12.4)$ & $2(2.8)$ & 0.03 \\
\hline Fever & $194(30.8)$ & $18(13.2)$ & 0.001 & 84 (38.5) & $11(15.2)$ & 0.001 \\
\hline Dyspnoea & $37(5.9)$ & $28(20.6)$ & 0.001 & $22(10.1)$ & $21(29.2)$ & 0.001 \\
\hline Lethargy & $30(4.8)$ & $10(7.4)$ & 0.22 & $9(4.1)$ & 6 (8.3) & 0.16 \\
\hline Reduced appetite & $37(5.9)$ & $16(11.8)$ & 0.70 & 18 (8.3) & $7(9.7)$ & 0.70 \\
\hline
\end{tabular}




\begin{tabular}{|c|c|c|c|}
\hline & $\begin{array}{l}\text { Younger patients } \\
\text { (18-64 years) }\end{array}$ & $\begin{array}{l}\text { Older patients } \\
(\geqslant 65 \text { years })\end{array}$ & p-value \\
\hline Patients & 679 & 344 & \\
\hline Patients with PTB & 243 (35.7) & 169 (49.1) & 0.001 \\
\hline $\begin{array}{l}\text { Patients with PTB with chest radiography reports } \\
\text { Chest radiography changes }\end{array}$ & 241 (99.2) & $97(57.4)$ & \\
\hline Cavitation & 44 (18.3) & 10 (10.3) & 0.001 \\
\hline Consolidation & $116(48.1)$ & $49(50.5)$ & 0.692 \\
\hline Nodules & $39(16.1)$ & 10 (10.3) & 0.165 \\
\hline Miliary & $7(2.9)$ & $4(4.1)$ & 0.568 \\
\hline Lymphadenopathy & 47 (19.5) & $4(4.1)$ & 0.001 \\
\hline Effusion & 33 (13.7) & $7(7.2)$ & 0.095 \\
\hline
\end{tabular}

\section{Timing of events}

Time to presentation (from symptom onset)

Considering all cases of TB, the median duration of symptoms at presentation to secondary care was longer in older patients (60 days) compared with younger patients ( 45 days), but this difference was not supported by statistical evidence $(\mathrm{p}=0.3) .27 .5 \%$ of older patients were symptomatic for $>4$ months compared with $21.0 \%$ of younger patients $(\mathrm{p}=0.53)$.

For PTB, the median duration of symptoms was 60 days in younger patients compared with 75 days in older patients, but this was not statistically significant $(\mathrm{p}=0.40)$. For pleural, intrathoracic and extrathoracic lymph node TB, the median duration in younger patients was 30, 30 and 50 days, respectively, and for older patients it was 26,30 and 60 days, respectively (supplementary table S1).

\section{Time from presentation (to starting treatment)}

For all TB cases, the median time from presenting in secondary care to starting treatment was shorter in younger compared with older patients: 3 versus 15 days $(p=0.001)$. For those with PTB, the median duration was 2 versus 7 days in younger versus older patients $(\mathrm{p}=0.001)$. The time to starting treatment for EPTB was also longer in older patients. For pleural, intrathoracic and extrathoracic lymph node TB, the median time in younger patients was 3,18 and 5 days, respectively, and for older patients it was 29, 42 and 11 days, respectively.

\section{Time to treatment (from symptom onset)}

Total time from symptom onset to starting treatment was $50 \%$ longer for older patients (91 days) than for younger patients ( 61 days) ( $\mathrm{p}=0.001$ ) for all patients with TB. The findings for those with PTB alone were similar at 61 versus 92.5 days in younger versus older patients with PTB (table 4). The total time from symptom onset to starting treatment was longer for older patients with EPTB. For pleural, intrathoracic and extrathoracic lymph node $\mathrm{TB}$, the median time in younger patients was 35, 63 and 61 days, respectively, and for older patients it was 54, 84 and 94 days, respectively.

\section{Across age groups}

Symptom duration at presentation to secondary care, time to starting treatment from presentation to secondary care and total time to start treatment from symptom onset to starting treatment are shown across age groups in figure 2. The median (IQR) time from secondary care to treatment for patients aged 65-74, 75-84 and 85-94 years was 18.5 (4-60), 13 (3-54) and 9 (2-36) days, respectively, compared with 6 (1-32) days for patients aged 55-64 years.

\section{Factors associated with time to treatment}

Age (as a continuous variable) was associated with longer time to presentation at secondary care (HR 0.98 (95\% CI 0.98-0.99) per year of age) (table 5), longer time to starting treatment (HR 0.98 (95\% CI 0.98-0.99) per year of age) (table 6) and longer time from symptom onset to starting treatment (HR 0.98 (95\% CI 0.98-0.99) per year of age) (table 7). These associations were unchanged in multivariable models when adjusted for other factors. 


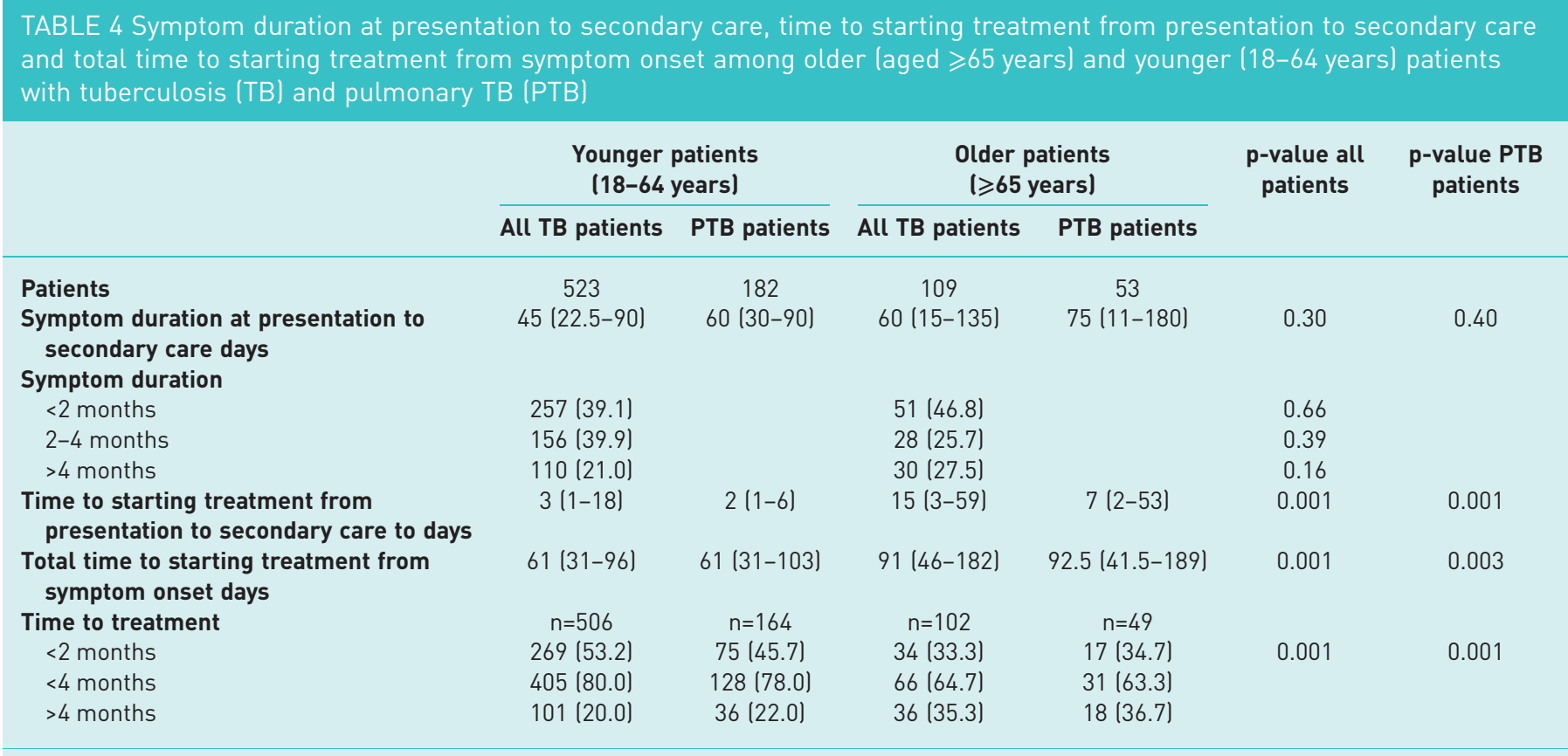

Data are presented as $\mathrm{n}$, median (interquartile range) or $\mathrm{n}(\%)$, unless otherwise stated.

When adjusted for age, the factors associated with a shorter time to presentation at secondary care were sex (male versus female) (HR 1.20 (95\% CI 1.03-1.34)), HIV (HR 2.08 (95\% CI 1.31-3.30)) and PTB versus EPTB (HR 1.17 (95\% CI 1.00-1.37)). Of these factors, only age and PTB versus EPTB remained as independent predictors in a multivariable model (HR 1.26 (95\% CI 1.05-1.50)) (table 5).

When adjusted for age, factors associated with a shorter time from presentation to secondary care included sex (male versus female), positive sputum smear, hypertension, cough, sweats and weight loss. A shorter time from presentation to starting treatment was associated with PTB versus EPTB. In a multivariable model, only age and sweats remained as independent predictors (table 6).

When adjusted for age, factors associated with a shorter time to treatment (from symptom onset) included sex (male versus female) (HR 1.23 (95\% CI 1.05-1.46)), UK born (HR 1.23 (95\% CI 1.05-1.46)) and HIV (HR 2.07 (95\% CI 1.30-3.29)). Only age remained as an independent predictor in a multivariable model adjusted for each of these variables (table 7 ).

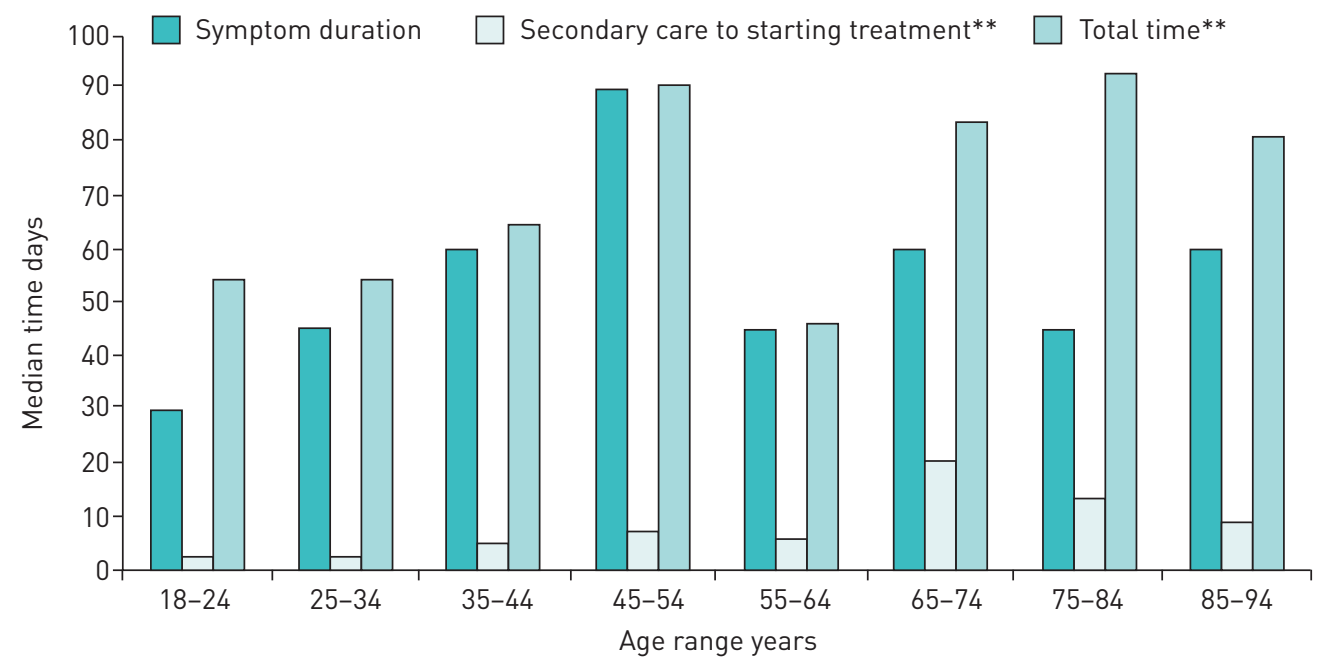

FIGURE 2 Symptom duration at presentation to secondary care, time to starting treatment from presentation to secondary care and total time to starting treatment from symptom onset. $* *$ : $p<0.01$. 


\section{TABLE 5 Factors associated with time to presentation (symptom duration) at secondary care}

\section{Crude HR $\left(95 \%\right.$ CI) Age-adjusted HR $\left(95 \%\right.$ CI $\quad$ Fully adjusted HR $(95 \% \text { CI })^{\#}$}

\begin{tabular}{|c|c|c|c|}
\hline Age & $0.98(0.98-0.99)$ & & $0.98(0.98-0.99)$ \\
\hline Sex (male versus female) & 1.19 (1.03-1.38) & $1.20(1.03-1.34)$ & $0.85(0.71-1.02)$ \\
\hline \multicolumn{4}{|l|}{ Ethnic group } \\
\hline Indian & $1.08(0.85-1.37)$ & & \\
\hline Pakistani & $1.10(0.79-1.53)$ & & \\
\hline Afghani & $0.58(0.46-0.73)$ & & \\
\hline White & $0.78(0.55-1.10)$ & & \\
\hline Bangladeshi & $1.03(0.62-1.72)$ & & \\
\hline Black & $0.91(0.67-1.22)$ & & \\
\hline Chinese & $4.27(3.22-5.67)$ & & \\
\hline HIV & $1.50(0.93-2.42)$ & $2.08(1.31-3.30)$ & $0.71(0.46-1.09)$ \\
\hline Diabetes & $1.26(1.01-1.58)$ & $1.09(0.85-1.40)$ & \\
\hline Hypertension & $1.19(0.96-1.46)$ & $1.01(0.80-1.30)$ & \\
\hline Renal failure & $1.11(0.90-1.37)$ & & \\
\hline Cancer & $1.33(0.82-2.16)$ & & \\
\hline \multicolumn{4}{|l|}{ Lung disease } \\
\hline Asthma/COPD & $1.59(0.58-4.33)$ & & \\
\hline Bronchiectasis & $1.28(0.54-3.00)$ & & \\
\hline ILD & $1.09(0.33-3.65)$ & & \\
\hline PE & $4.04(1.48-11.00)$ & & \\
\hline РТВ versus ЕРТВ & $1.20(1.03-1.38)$ & $1.17(1.00-1.37)$ & $1.26(1.05-1.50)$ \\
\hline
\end{tabular}

\section{Discussion}

In this cohort, older age was associated with a longer time from symptom onset to starting treatment for TB. Symptom duration at presentation to secondary care did not differ between the two groups and the overall difference was attributed to longer time to starting treatment after presentation to secondary care. A greater proportion of older patients were symptomatic for $>4$ months compared with younger patients. The clinical and radiological presentations of older patients were different to younger patients with TB: older patients had fewer of the "classical" symptoms of TB and more non-TB specific symptoms, including dyspnoea and lethargy. Cavitation, nodules, lymphadenopathy and effusions were more common on chest radiography in younger than in older patients.

The higher proportion of South Asian patients noted in the younger age group with active TB is likely to represent trends in immigration to the UK, where we typically observe the phenomenon of young Asian males living in low-rental areas of London where there is a community of their compatriots and having full-time or part-time low-paid jobs in food or other factories or in construction. This and the peak of TB in this age group may give a biased perception of the "typical" patient with TB in the UK, perhaps contributing to a lower index of clinical suspicion of TB in older or White patients. Public Health England reported that $25 \%$ of patients with PTB commenced treatment at least 4 months after symptom onset, but this proportion increased to $33 \%$ of UK-born cases and $35 \%$ of those aged $\geqslant 65$ years [22].

The difference in clinical presentation has been borne out in other studies in Turkey [6, 23], although some report a similar prevalence of respiratory symptoms [24]. The differences in clinical and radiological presentations are likely as a result of the effect of immunosenescence on the characteristics of TB in older compared with younger patients with TB; similar distortions occur in other immunocompromised states, e.g. HIV [25]. It has long been hypothesised that TB in the elderly results from reactivation of LTBI rather than recently acquired infection. TB prevalence in England before the advent of chemotherapy in the 1950s was high and UK-born older patients may have developed LTBI in childhood or early adulthood [26]. Changes relating to immunosenescence, or the onset of comorbidities which influence the immune system, may contribute to reactivation $[1,12,13,27]$. Generally, LTBI reactivation is most likely to occur within 18 months of exposure [28]. This is unlikely to be the case in our older patients, because rates of transmission of TB in London are low [22]. The exception may be where the elderly live in a closed environment, with nursing home residents having an increased risk of TB [29]. Some older studies that describe drug resistance across age groups show that monoresistance (to isoniazid or streptomycin) in 


\begin{tabular}{|c|c|c|c|}
\hline & Crude HR $(95 \% \mathrm{CI})$ & Age-adjusted HR $(95 \% \mathrm{CI})$ & Fully adjusted HR $(95 \% \mathrm{Cl})^{\#}$ \\
\hline Age & $0.98(0.98-0.99)$ & & $0.98(0.98-0.99)$ \\
\hline Sex (male versus female) & $1.17(1.01-1.35)$ & $1.19(1.01-1.38)$ & $1.09(0.94-1.29)$ \\
\hline \multicolumn{4}{|l|}{ Ethnic group } \\
\hline Indian & $1.03(0.84-1.26)$ & & \\
\hline Pakistani & $0.75(0.49-1.17)$ & & \\
\hline Afghani & $0.24(0.19-0.29)$ & & \\
\hline White & $0.90(0.63-1.28)$ & & \\
\hline Bangladeshi & $1.16(0.61-2.21)$ & & \\
\hline Black & $0.94(0.71-1.24)$ & & \\
\hline Chinese & $0.89(0.49-1.64)$ & & \\
\hline UK born & $0.96(0.71-1.31)$ & $1.00(0.72-1.40)$ & \\
\hline Sputum smear & $1.09(1.01-1.18)$ & $1.10(1.01-1.20)$ & $1.09(0.90-1.32)$ \\
\hline TB sensitivity & $1.27(1.11-1.44)$ & $0.84(0.70-1.01)$ & \\
\hline HIV & $1.03(0.74-1.43)$ & & \\
\hline Diabetes & $1.36(1.13-1.64)$ & $1.14(0.92-1.40)$ & \\
\hline Hypertension & $1.55(1.29-1.87)$ & $1.33(1.06-1.67)$ & $0.86(0.65-1.12)$ \\
\hline Renal failure & $1.28(1.13-1.46)$ & $1.16(0.99-1.35)$ & \\
\hline Cancer & $1.54(1.20-1.97)$ & $1.23(0.90-1.69)$ & \\
\hline \multicolumn{4}{|l|}{ Lung disease } \\
\hline Asthma/COPD & $0.83(0.29-2.37)$ & & \\
\hline Bronchiectasis & $3.16(0.99-10.1)$ & & \\
\hline ILD & $1.27(0.39-4.19)$ & & \\
\hline $\mathrm{PE}$ & $1.22(3.91-3.78)$ & & \\
\hline Sarcoid & $1.10(0.42-2.90)$ & & \\
\hline РTВ versus EРTB & $0.74(0.64-0.86)$ & $0.70(0.60-0.82)$ & $1.10(0.90-1.34)$ \\
\hline Cough & $1.22(1.06-1.40)$ & $1.22(1.06-1.41)$ & $0.97(0.81-1.15)$ \\
\hline Sweats & $1.38(1.18-1.61)$ & $1.33(1.12-1.56)$ & $1.24(1.02-1.51)$ \\
\hline Weight loss & $1.24(1.08-1.43)$ & $1.25(1.08-1.44)$ & $1.03(0.87-1.22)$ \\
\hline
\end{tabular}

older patients is only slightly lower than in younger patients, suggesting that recent transmission may be important [30, 31].

In our study, we find that EPTB is significantly more common among younger patients than PTB (64\% versus $35 \%$ ) compared with $\sim 50 \%$ of each among older patients. There is some tentative evidence in the literature that PTB is more common than EPTB among older patients, which would be consistent with TB in the elderly being predominantly as a result of reactivation. TEALE et al. [32] reported that PTB accounted for $87 \%$ of cases in the elderly compared with $75 \%$ of cases in younger patients in the UK. Another study (in India) found PTB to be similar at 75\% in older patients and $73 \%$ in younger patients; the most common site of EPTB in older patients was TB lymphadenitis [9]. The different ratios of EPTB and PTB in older and younger patients in our cohort is possibly related to the pattern of reactivation and differences of presentation of TB resulting from immunosenescence related to ageing [33]. There are few phylogenetic studies that characterise this in older populations. A Japanese variable number tandem repeat study analysed 387 strains of Mycobacterium tuberculosis among elderly patients and found that $9.7 \%$ of the cases were attributable to recent transmission; this supports the suggestion that TB in this population is as a result of endogenous reactivation from infection at a time when TB was more prevalent [34]. Another explanation for the difference may also relate to differences in dominant ethnicities, with South Asian ethnicity more common in the younger age group compared with White ethnicity in the older age group; both age and ethnicity have been shown to influence the site of TB, with EPTB being more common among ethnicities from outside of Europe [35].

There are few studies that compare treatment delays in the UK between younger and older patients. LEWIS et al. [36] found an overall delay of 126 days, which is longer than in our cohort; the median duration of symptoms was similar at 63 days, but the healthcare delay was longer at 35 days. The contribution of primary versus secondary care delays was not clarified, making direct comparison with our study difficult. 


\section{TABLE 7 Factors associated with time to starting treatment from symptom onset}

Crude HR $\left(95 \%\right.$ CI) Age-adjusted HR $\left(95 \%\right.$ CI) Fully adjusted HR $(95 \% \mathrm{CI})^{\#}$

$0.98(0.98-0.99)$

$0.98(0.98-0.99)$

Age
Sex (male versus female)
Ethnic group
UK born
Sputum smear
TB sensitivity
HIV
Diabetes
Hypertension
Renal failure
Cancer
Lung disease
Asthma/COPD
Bronchiectasis
ILD
PE
Sarcoid
PTB versus EPTB
Cough
Sweats
Weight loss

$1.22(1.04-1.43)$

$0.98(0.94-1.02)$

$0.92(0.67-1.27)$

$0.98(0.90-1.07)$

$1.14(0.99-1.32)$

$1.37(0.93-2.02)$

$1.55(1.21-1.99)$

$1.40(1.13-1.73)$

$1.22(0.99-1.51)$

1.27 (0.82-1.98)

$1.78(0.67-4.69)$

$2.26(0.74-6.90)$

$1.41(0.32-6.16)$

$5.64(1.87-17.01)$

$28.2(5.91-124.76)$

$1.01(0.93-1.30)$

1.07 (0.91-1.25)

$1.22(1.03-1.44)$

0.90 (0.77-1.05)

$1.23(1.05-1.46)$

$0.98(0.95-1.02)$

$1.23(1.05-1.46)$

$0.97(0.88-1.06)$

$0.98(0.82-1.18)$

$2.07(1.30-3.29)$

$1.26(0.97-1.64)$

$1.14(0.90-1.44)$

$1.11(0.86-1.45)$

HR: hazard ratio; TB: tuberculosis; COPD: chronic obstructive pulmonary disease; ILD: interstitial lung disease; PE: pulmonary embolism; PTB: pulmonary tuberculosis; EPTB: extrapulmonary tuberculosis. \#: adjusted for age, sex, UK born and HIV.

Another UK study found that female sex and older age were contributors to delays in starting treatment [37]. Of note, we did not find ethnicity to be a cause of delay; however, the numbers of White patients in this study are small ( 42 in those aged $18-65$ years and 53 in those aged $\geqslant 65$ years), which may account for this. Time to starting treatment from presentation to secondary care was shorter for EPTB compared with PTB in this cohort, which differs from published studies [38]. This is likely due to the rapidity with which diagnostics are carried out and treatment initiated in EPTB patients at this site, e.g. lymph node or pleural aspirate compared with awaiting sputum samples or bronchoalveolar lavage for patients with PTB.

A UK study using data routinely collected between 1999 and 2000 showed that White ethnicity, female sex and older age contributed to delays in the West Midlands [39]. A North London study in 2004 reported delays between 78 and 99 days, comprising patient-related delays of 35-54 days and healthcare system delays of 30 days. Shorter delays occurred in patients from high-prevalence countries, younger patients and those with smear-positive disease [40]. The difference in time to starting treatment may relate to the more classical symptoms of TB evident in younger patients or the absence of comorbidities that alter the course of TB. Concerns about drug interactions, polypharmacy or drug side-effects in older patients may influence the decision to start TB treatment.

TB mortality increases with age [41]. In 2015, there were 1.8 million TB-related deaths worldwide [42]; in 2014, in the UK, of the 6405 with sensitive TB, 5.5\% had death as an outcome [22], with those aged $\geqslant 65$ years accounting for $66.4 \%$ of deaths [22]. According to the 2010 Global Burden of Disease estimates, $>50 \%$ of TB deaths occur in those aged $\geqslant 65$ years internationally [4]. In the UK, those aged $\geqslant 65$ years accounted for $66.4 \%$ of 351 deaths [22]. In a Chinese study, those aged $\geqslant 65$ years had twice the risk of death as those aged 18-64 years [43]. In the UK, deaths are broken down to further categories, as older patients may also die of other causes where TB is not the main cause, may be a contributor or may not be contributing [22]. However, the higher proportion of deaths accounted for by older patients with TB supports the need to invest in measures to ensure the appropriate investigation and management of older patients with TB.

A constraint of this study is that presentation at secondary care rather than primary care is taken as the time-point for presenting to healthcare, because this was readily available from the databases. There may have been more incorrectly recorded data for older patients (because we used data from 2002 to 2015), but this is unlikely to bias our measures of effect. Bias could have occurred in relation to recall of time of symptom onset, if older patients tended to recall longer or shorter time since onset. This can be hard to 
address, although obtaining primary healthcare records from where patients were initially seen could corroborate reported symptoms and durations. In addition, missing data occurred in a greater proportion of older patients compared with younger patients. This is due to the different time periods, with more radiography reports available in later time periods. However, given the magnitude of the differences noted, this is unlikely to alter the results that are statistically significant.

In summary, our analysis of data from a large UK cohort of TB patients has demonstrated different clinical and radiological presentations between older and younger TB patients, and longer time to TB treatment for older patients, which was a cumulative effect of longer time to presentation and longer time from presentation to initiation of treatment. These differences may relate to the lower index of suspicion of TB in the elderly, but also to the effect of immunosenescence on the classical presentations of TB. These findings relate to an urban cohort that had a high burden of $\mathrm{TB}$ during the study period in a country that has a low incidence of TB and they will be applicable in similar settings in Western Europe.

Acknowledgements: We would like to thank the tuberculosis nurses and the Research and Development Dept of London North West University Healthcare NHS Trust. O.M. Kon is affiliated to the National Institute for Health Research (NIHR) Health Protection Research Unit in Respiratory Infections at Imperial College London in partnership with Public Health England (PHE). The views expressed are those of the author and not necessarily those of the National Health Service, the NIHR, the Dept of Health or PHE. O.M. Kon is also supported by the NIHR Imperial Biomedical Research Centre.

Author contributions: A. Abbara, O.M. Kon, T. Hansel, L. John and R.N. Davidson designed the study. A. Abbara, K. Buell, A. Sullivan and J. Barrett collected the required data. S.M. Collin supported the design and statistical analysis of the study. A. Abbara, S.M. Collin, J. Barrett, T. Corrah, A. McGregor, T. Hansel, L. John and R.N. Davidson contributed to the writing, corrections and review of the manuscript.

Support statement: No funding was received directly for this work, although A. Abbara's salary was paid by the Research and Development Dept of London North West University Healthcare NHS Trust.

Conflict of interest: None declared.

References

1 Byng-Maddick R, Noursadeghi M. Does tuberculosis threaten our ageing populations? BMC Infect Dis 2016; 16: 119.

2 World Health Organization. Global Health and Aging. 2010. www.who.int/ageing/publications/global_health.pdf Date last accessed: September 2, 2019.

3 World Health Organization. Tuberculosis Global Report. 2016. https://apps.who.int/iris/bitstream/handle/10665/ 250441/9789241565394-eng.pdf Date last accessed: September 2, 2019.

4 Negin J, Abimbola S, Marais BJ. Tuberculosis among older adults - time to take notice. Int J Infect Dis 2015; 32 $135-137$.

5 Ananthakrishnan R, Kumar K, Ganesh M, et al. The profile and treatment outcomes of the older (aged 60 years and above) tuberculosis patients in Tamilnadu, South India. PLoS One 2013; 8: e67288.

6 Tatar D, Senol G, Alptekin S, et al. Tuberculosis in older adults. Eur Geriatr Med 2013; 4: 15-19.

7 Korzeniewska-Kosela M, Krysl J, Müller N, et al. Tuberculosis in young adults and the elderly. A prospective comparison study. Chest 1994; 106: 28-32.

8 Chan-Yeung M, Noertjojo K, Tan J, et al. Tuberculosis in the elderly in Hong Kong. Int J Tuberc Lung Dis 2002; 6: 771-779.

9 Bhushan B, Kajal NC, Maske A, et al. Manifestations of tuberculosis in elderly versus young hospitalised patients in Amritsar, India. Int J Tuberc Lung Dis 2012; 16: 1210-1213.

10 Morris CD. The radiography, haematology and biochemistry of pulmonary tuberculosis in the aged. Q $J$ Med 1989; 71: 529-536.

11 Chan $\mathrm{CH}$, Woo J, Or KK, et al. The effect of age on the presentation of patients with tuberculosis. Tuber Lung Dis 1995; 76: 290-294.

12 Wang C-S, Chen HC, Yang CJ, et al. The impact of age on the demographic, clinical, radiographic characteristics and treatment outcomes of pulmonary tuberculosis patients in Taiwan. Infection 2008; 36: 335-340.

13 Morris CD. Pulmonary tuberculosis in the elderly: a different disease? Thorax 1990; 45: 912-913.

14 Pérez-Guzmán C, Vargas MH, Torres-Cruz A, et al. Does aging modify pulmonary tuberculosis? A meta-analytical review. Chest 1999; 116: 961-967.

15 Public Health England. Tuberculosis in the UK: 2014 Report. 2014. https://assets.publishing.service.gov.uk/ government/uploads/system/uploads/attachment_data/file/360335/TB_Annual_report_4_0_300914.pdf Date last accessed: September 2, 2019.

16 Cai J, Wang X, Ma A, et al. Factors associated with patient and provider delays for tuberculosis diagnosis and treatment in Asia: a systematic review and meta-analysis. PLoS One 2015; 10: e0120088.

17 Liaw YS, Yang PC, Yu CJ, et al. Clinical spectrum of tuberculosis in older patients. J Am Geriatr Soc 1995; 43: 256-260.

18 Hussein MT, Yousef LM, Abusedera MA. Pattern of pulmonary tuberculosis in elderly patients in Sohag Governorate: hospital based study. Egypt J Chest Dis Tuberc 2013; 62: 269-274.

19 Pirkis JE, Speed BR, Yung AP, et al. Time to initiation of anti-tuberculosis treatment. Tuber Lung Dis 1996; 77: 401-406. 

pulmonary tuberculosis patients in rural Nigeria: a cross-sectional study. BMC Health Serv Res 2013; 131: 233-239.

21 Thomas TY, Rajagopalan S. Tuberculosis and aging: a global health problem. Clin Infect Dis 2001; 33: 1034-1039.

22 Public Health England. Tuberculosis in England: 2016 Report. 2016. www.tbalert.org/wp-content/uploads/2016/ 09/PHE_TB_Annual_Report_2016.pdf Date last accessed: September 2, 2019.

23 Yoshikawa TT. Tuberculosis in aging adults. J Am Geriatr Soc 1992; 40: 178-187.

24 Umeki S. Clinical features of pulmonary tuberculosis in young and elderly men. Jpn J Med 1989; 28: $341-347$.

25 Swaminathan S, Padmapriyadarsini C, Narendran G. HIV-associated tuberculosis: clinical update. Clin Infect Dis 2010; 50: 1377-1386.

26 Vynnycky E, Fine PE. Interpreting the decline in tuberculosis: the role of secular trends in effective contact. Int $J$ Epidemiol 1999; 28: 327-334.

27 Schaaf HS, Collins A, Bekker A, et al. Tuberculosis at extremes of age. Respirology 2010; 15: 747-763.

28 Esmail H, Barry CE, Young DB, et al. The ongoing challenge of latent tuberculosis. Philos Trans R Soc Lond B Biol Sci 2014; 369: 20130437.

29 Centers for Disease Control and Prevention. Prevention and Control of Tuberculosis in Facilities Providing Long-Term Care to the Elderly. Recommendations of the Advisory Committee for Elimination of Tuberculosis 1990. www.cdc.gov/mmwr/preview/mmwrhtml/00001711.htm Date last accessed: January 22, 2017.

30 Canetti G, Sutherland I, Svandova E. Endogenous reactivation and exogenous reinfection: their relative importance with regard to the development of non-primary tuberculosis. Bull Int Union Tuberc 1972; 47: 116-134.

31 Behr MA, Edelstein PH, Ramakrishnan L. Revisiting the timetable of tuberculosis. BMJ 2018; 362 : k2738.

32 Teale C, Goldman JM, Pearson SB. The association of age with the presentation and outcome of tuberculosis: a five-year survey. Age Ageing 1993; 22: 289-293.

33 Kaufmann SHE. How can immunology contribute to the control of tuberculosis? Nat Rev Immunol 2001; 1: 20-30.

34 Seto J, Wada T, Suzuki Y, et al. Mycobacterium tuberculosis transmission among elderly persons, Yamagata Prefecture, Japan, 2009-2015. Emerg Infect Dis 2017; 23: 448-455.

35 Sotgiu G, Falzon D, Hollo V, et al. Determinants of site of tuberculosis disease: an analysis of European surveillance data from 2003 to 2014. PLoS One 2017; 12: e0186499.

36 Lewis KE, Stephens C, Shahidi MM, et al. Delay in starting treatment for tuberculosis in east London. Commun Dis Public Health 2003; 6: 133-138.

37 Rodger A, Jaffar S, Paynter S, et al. Delay in the diagnosis of pulmonary tuberculosis, London, 1998-2000: analysis of surveillance data. BMJ 2003; 326: 909-910.

38 Jørstad MD, Aßmus J, Marijani M, et al. Diagnostic delay in extrapulmonary tuberculosis and impact on patient morbidity: a study from Zanzibar. PLoS One 2018; 13: e0203593.

39 Sultan H, Haroon S, Syed N. Delay and completion of tuberculosis treatment: a cross-sectional study in the West Midlands. J Public Health 2013; 35: 12-20.

40 Paynter S, Hayward A, Wilkinson P, et al. Patient and health service delays in initiating treatment for patients with pulmonary tuberculosis: retrospective cohort study. Int J Tuberc Lung Dis 2004; 8: 180-185.

41 Salvadó M, Garcia-Vidal C, Vásquez P et al. Mortality of tuberculosis in very old people. J Am Geriatr Soc 2010; 58: $18-22$.

42 Centers for Disease Control and Prevention. TB Data and Statistics. 2015. www.cdc.gov/tb/statistics Date last accessed: December 10, 2016.

43 Abuaku B, Tan H, Li X, et al. Treatment default and death among tuberculosis patients in Hunan, China. Scand J Infect Dis 2010; 42: 281-287. 